\title{
Analysis of role of design in furniture production and market by applying ANP
}

\begin{abstract}
This study was carried out due to the severe dearth of research on the role of design in the country's furniture production and market. Accordingly this research represent a decision making model developed to select best solution of role of design in the industry. Four possibilities can be considered as potential solutions: using fashion design in furniture production (S1), using engineering design in furniture production (S2), using a combination of fashion and engineering designs in furniture production (S3), applying leading countries' design capability with an outsourcing approach in furniture production (S4). The Analytic Network Process and the Super Decision software were used to synthesize and analyze the model. In was found that all calculated decisions were influenced by strategic criteria. A value-weighted competency model was calculated in the first stage with the influence of strategic criteria on the competency model. Hierarchical designs decisions were made for each of the competencies and their subsets (298 sub criteria and 31 middle indices). Paired comparison matrices associated with the degree of importance of each of the competencies were achieved in the second stage. In the final stage, subsets of competencies' weights and their sub-options were identified with the combination of the competencies and the best solution was obtained.
\end{abstract}

Key words: Analytic Network Process, Strategic criteria, Benefits, Opportunities, Costs, Risks, Furniture, Design

\section{Introduction}

The design of new furniture is usually done with three purposes including: structure design i.e. the physical shape and appearance of furniture, the raw materials used, and manufacturing technology. New design of product and technological factors are factors for development in furniture industry in Southeast Asia (Ratnasingam and Ioras, 2003). The use of design is very widespread, for example, design for performance, requesting modification in terms of aesthetics, ease of production, sustainability, and reliability, quality, and business processes.

\section{Hypotheses/Objectives}


Identifying the best solutions for the use of the role of design in furniture production and its market improvement.

\section{Literature Review}

In a study, Swann \& Birke (2005) showed that creativity and design influence R\&D through channels. As inputs, creativity and design play an important role in the innovation and performance of a business. Research conducted for this study also show that companies with a higher intensity of design more likely produce the product with innovation. Design costs have a positive correlation with the company's productivity growth (Bessant, Whyte and Neely, 2005), A study by Gemser and Leenders (2001) on Dutch companies shows that design integration in the development projects of new product has a significant positive impact on the company performance (profit, turnover, sales, and exports). A model aiming the usage of ANP in supplier selection is developed and implemented in an electronic company (Gencer and Gurpinar, 2007). ANP models are also used for locating facilities strategically (Partovi, 2006), selection of the appropriate energy policy for Turkey (Ulutas, 2005), and for product mix planning in semiconductor fabricator (Chang, et al. 2005).

\section{Research Design/Methodology}

The aim of this study is to develop a decision network model to address the finding best solution of role of design in the country's furniture production and market. In the network model, merits are divided into four subsections as benefits, opportunities, costs and risks (BOCR). These merits are influenced by strategic criteria (political, legal, development and technological, cultural and social and economic factors) to obtain weighting values for each. This process follows the principle of analytic network process (ANP). There are 296 sub criteria in 31 middle criteria and five main group (marketing and economic, technical and man force, supply and production, social \& cultural and environmental). Weighing values of criteria and sub criteria obtained by pairwise comparisons and feed backs between criteria, sub criteria and four solutions.

\section{Data/Model Analysis}

\section{Prioritizing BOCR}

To categorize the criteria which have been used in current research we divided them as favorable and unfavorable categories. The decision maker considers the favorable criteria as benefits and the unfavorable criteria as costs. The possible events are also divided into opportunities and risks criteria, depending whether they are considered to be positive or negative (Saaty, 2001).

Since BOCR are not equally important, it is necessary to prioritize them. Five possible ratings ranging from "very high" to "very low" are used. The results of the influence of the strategic criteria on the merits of benefits, costs, opportunities, risks, and the priority of the above mentioned merits are reported in Table 1. 


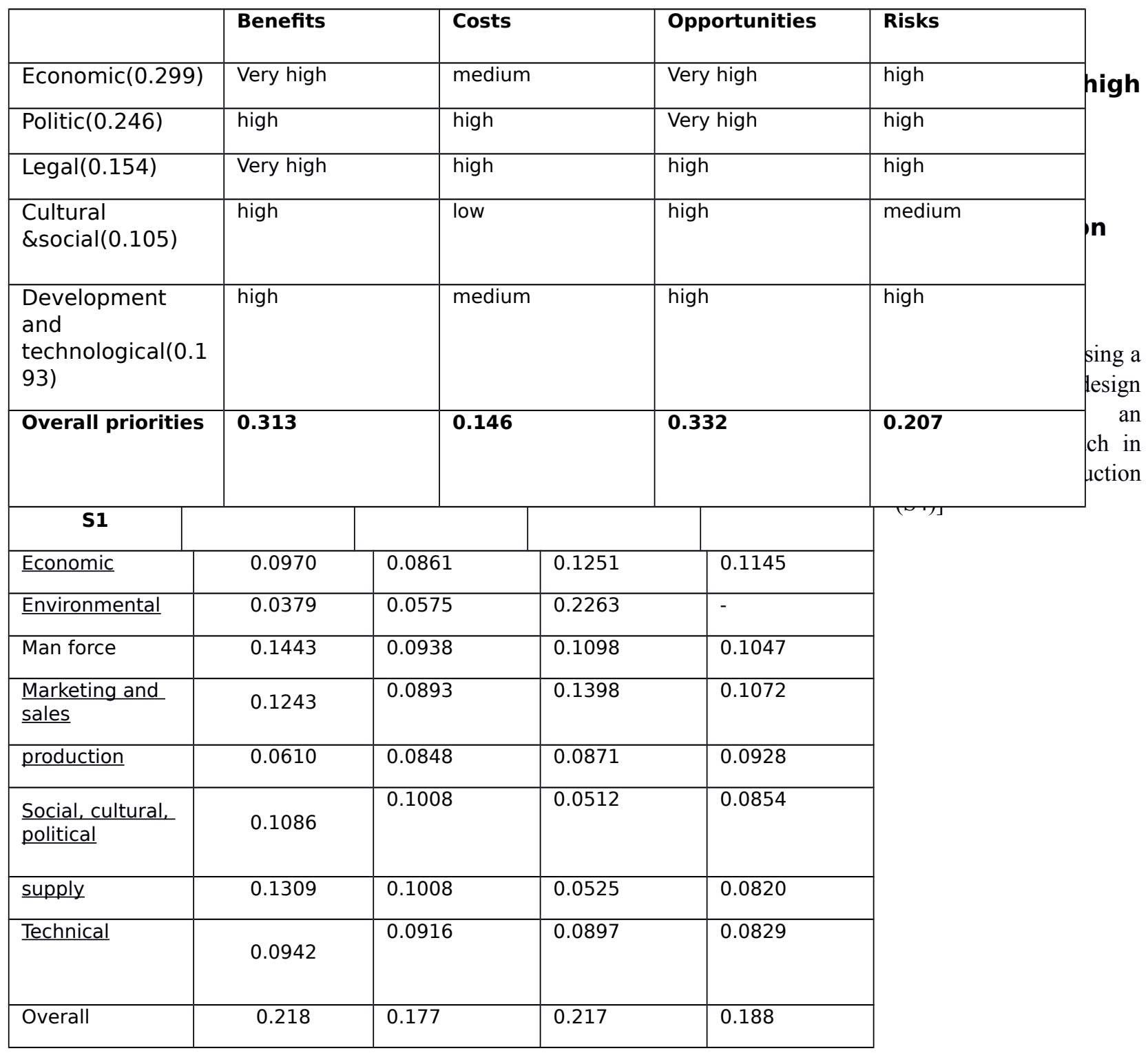

Table 3: Results of priorities of Critical criteria with respect to BOCR for solution S2 


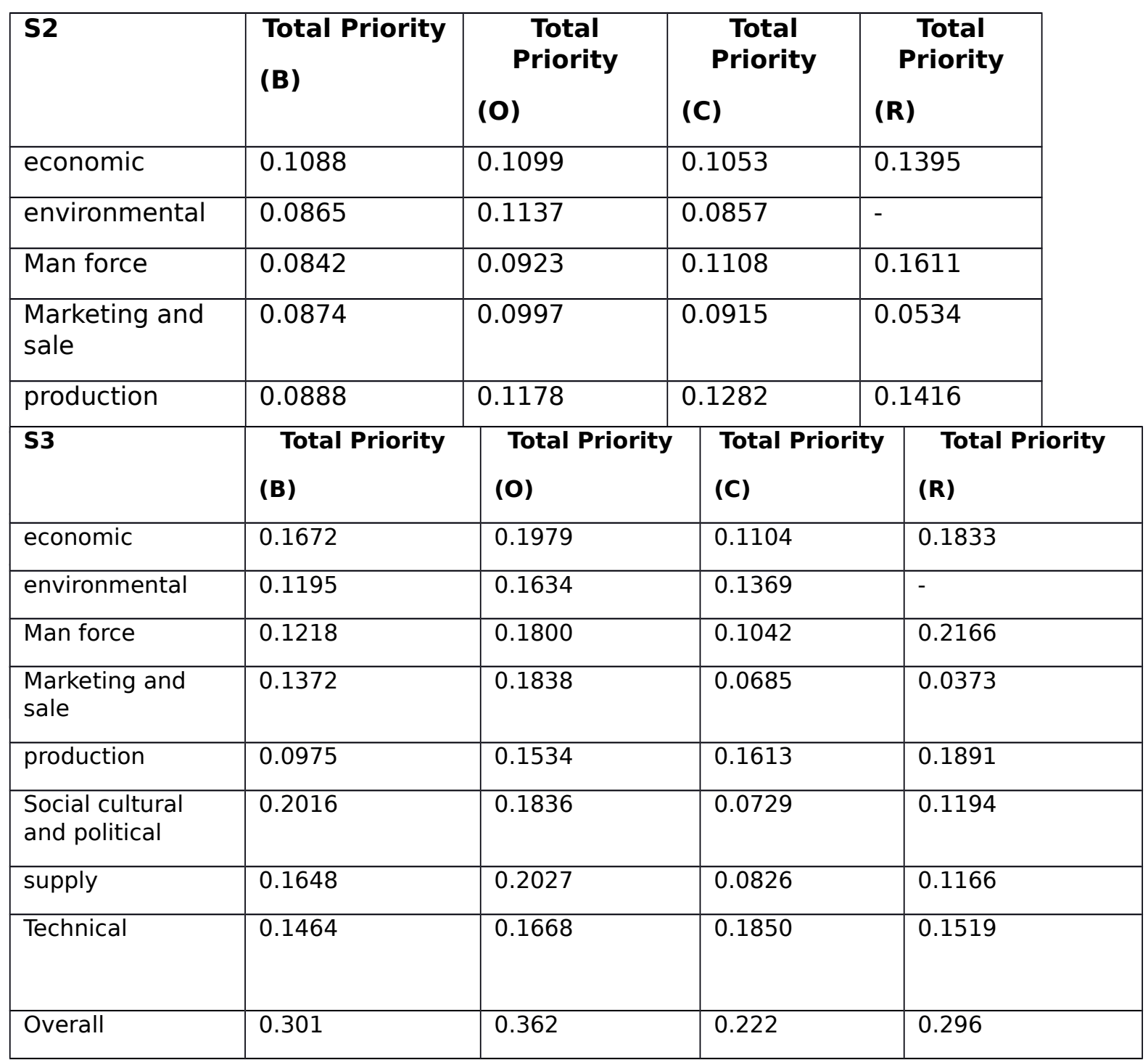

Table 4: Results of priorities of Critical criteria with respect to BOCR for solution S3

Table 5: Results of priorities of Critical criteria with respect to BOCR for solution S4

\begin{tabular}{|l|l|l|l|l|}
\hline S4 & $\begin{array}{l}\text { Total Priority } \\
\text { (B) }\end{array}$ & $\begin{array}{l}\text { Total Priority } \\
\text { (O) }\end{array}$ & $\begin{array}{c}\text { Total } \\
\text { Priority }\end{array}$ & $\begin{array}{c}\text { Total Priority } \\
\text { (R) }\end{array}$ \\
\hline
\end{tabular}




\begin{tabular}{|l|l|l|l|l|}
\hline & & & (C) & \\
\hline economic & 0.1321 & 0.1321 & 0.1592 & 0.1198 \\
\hline environmental & 0.2747 & 0.1653 & 0.0511 & - \\
\hline Man force & 0.1414 & 0.1338 & 0.1752 & 0.0530 \\
\hline $\begin{array}{l}\text { Marketing and } \\
\text { sale }\end{array}$ & 0.1361 & 0.0984 & 0.2002 & 0.3021 \\
\hline production & 0.1437 & 0.1299 & 0.1235 & 0.0765 \\
\hline $\begin{array}{l}\text { Social cultural } \\
\text { and political }\end{array}$ & 0.0794 & 0.1440 & 0.2580 & 0.2085 \\
\hline supply & 0.0488 & 0.1113 & 0.2250 & 0.2150 \\
\hline $\begin{array}{l}\text { Technical } \\
\text { Overall }\end{array}$ & 0.1326 & 0.1127 & 0.0703 & 0.1466 \\
\hline
\end{tabular}

By integration of the weights of the merits of benefits, costs, opportunities and risks and the weights of choices against the above mentioned merits, the final scores are reported in Table 6.

Table 6: Final Outcome for Priorities of the Alternatives

\begin{tabular}{|c|c|c|c|c|c|c|}
\hline Mer. & $\begin{array}{c}\text { Benefits } \\
\qquad \begin{array}{c}\mathbf{0 . 3 1} \\
\mathbf{3})\end{array}\end{array}$ & $\begin{array}{l}\text { Opportunitie } \\
\text { s } \\
\qquad(\mathbf{0 . 3 3 2})\end{array}$ & $\begin{array}{l}\text { Costs } \\
\qquad \begin{array}{l}(\mathbf{0 . 1 4} \\
\mathbf{6})\end{array}\end{array}$ & $\begin{array}{l}\text { Risks } \\
\qquad \begin{array}{l}(\mathbf{0 . 2 0} \\
\mathbf{7})\end{array}\end{array}$ & $\begin{array}{l}\text { Final } \\
\text { Outcome } \\
\text { Additive }\end{array}$ & $\begin{array}{l}\mathrm{Ra} \\
\mathrm{nk} \\
\text { in } \\
\mathrm{g}\end{array}$ \\
\hline S1 & 0.218 & 0.177 & 0.217 & 0.188 & 0.225 & 2 \\
\hline S2 & 0.228 & 0.211 & 0.233 & 0.227 & 0.217 & 3 \\
\hline S3 & 0.301 & 0.362 & 0.222 & 0.296 & 0.396 & 1 \\
\hline S4 & 0.252 & 0.249 & 0.327 & 0.287 & 0.161 & 4 \\
\hline
\end{tabular}

As Table 6 shows, using a combination of fashion and engineering designs in furniture production (S3) has the highest priority, and is the most suitable solution for using design role in furniture's production and marketing. The second, third and fourth are Using fashion design in furniture production (S1), using engineering design in furniture production (S2), and applying leading countries' design capability with an outsourcing approach in furniture production

(S4) respectively.

\section{Conclusions}


The final result of Strategic Criteria shows that economic factors with a weight of 0.29 are the most important ones. For managers and employers of the country's furniture industry, these factors are more effective than other factors in influencing people's decision making role. Also, BOCR indicates that opportunities have higher significance than other competencies regarding the role of design in the production and furniture market. In terms of selection, the third solution (S3) or the use of the combination of fashion design and engineering design in the marketplace and furniture manufacturing is considered the best solution. Accordingly, we can list the following with respect to the control criteria: Economic Index: If this solution (S3) is planned and implemented by companies and furniture manufacturing workshops in the country, the maximum use of available capacities in the scientific and technological infrastructure of universities is provided. And it can be considered a serious competitor along with other foreign competitors to protect the share of the country's furniture and furniture market in favor of domestic power. This solution creates a new competitive advantage based on the relative advantages of the country in order to take advantage of domestic and self-reliance on furniture design and production. In the area of foreign investment in the field of furniture manufacturing, the implementation of this strategy will drive the country's production of furniture to high value added products and can plan investment contracts in the country with the condition of transferring technical knowledge and transferring the way of doing business given the capacity of graduates who can design in scientific infrastructure of the country. Marketing and sale index: Using the solution (S3) in the market and furniture industry of the country, it is possible to restore the potential of the country to brand Iranian furniture and create the ground for the emergence and prosperity of Iranian brands in the international market because most of the major exporter countries have been able to use fashion design and engineering design capabilities simultaneously and create strong and reputable brands in their global markets and gain a good market share. Through the design of new and diverse products in the market, which, in addition to having a beautiful and colorful color, and different prices, have the right structural and ergonomic power, they attract and enhance customers and market development. Supply index: the third solution (S3) can be used to design and manage the use of indigenous and even nonindigenous materials in design. One use of furniture products such as fabric, foam, paint, metal, glass and fittings, one will also work reliably and will not be concerned about the cessation of its supply, and if there were problems, suitable alternatives could be found by trial and error. 
Production index: the use of solution (S3) leads to the creation or development of R \& D unit in companies that can be overwhelming with the benefits and interests for companies, so that by designing the product, any trial and error caused by the production of a product reduces to the minimum possible, and with a precise understanding of the execution plan by the operator, redoing caused by human error reduces, which has the highest contribution in reducing the efficiency of production, thus the accuracy and quality of work increases, but the production time decreases. By identifying the production time of product, it can be ascertained as to the timing of the production of each product, and can provide a fair judgment of labor productivity. Also, with the planning of production capacity and per capita production for each individual, the productivity of the workforce can be marvelously enhanced by some incentives. Reducing duplication and increasing production efficiency will lead to savings in raw material consumption and, on the other hand, by increasing labor productivity and reducing human error, the production time of a product will be reduced and production will increase. Furthermore, the positive outcome of these events in production leads to lower production costs and increased margins, which, in addition to raising the competitiveness of the product, leads to the timely scheduling and delivery of production orders. On the other hand, with the proper design of the product, it is possible to assess and study the packaging of the product in various forms, so that in the case of export, the shipping costs would be reduced significantly by proper packaging of the product. Technical Index: using the third solution (S3), a design change can always be made to a product that is not in line with competitors' products, and has a distinction and difference with other products. If the use of new machines is not mandatory, a market share can only be achieved by differentiating the design. The development of modular furniture is an example of this distinction in design. In addition, it is possible to issue technical and engineering services in the field of product design and set up of production units in other countries and provide an appropriate valuation for the country. It also provides for the development of design and ergonomics, and can design and manufacture products in accordance with national and international anthropometric standards that, in addition to the beauty and elegance in terms of structural strength and bearing loads, can match the standards of the day. Man force index: the third solution (S3) offers the possibility of job creation for college graduates in the fields of architecture, art, industrial design, and wood industry, and they can operate in the field of designing and producing new products by establishing new knowledge-based companies. 
Universities can also produce industry-specific portfolio designs for the furniture industry, tailormade with up-to-date designs. Social, cultural, and political index: using the third solution (S3), a sense of self-confidence is created in the domestic producer. It is possible to respond to customer needs. Designing in accordance with the culture of the community, in the form of national furniture and creating unique charm, while respecting the customer's sensitivity, the industry is restored and is being offered to world markets. If we can continuously apply beauty, quality, precision, elasticity, and elegance in the field of furniture production, over time, a national cultural dimension will be formed internationally, indicating quality and trust in the furniture of the country. Environmental indicator: using the combination of fashion and engineering design (S3), we can use the optimal amount of raw materials available to reduce the harvest and utilization of forest resources. With the principled design, it is possible to recycle most of the consumables in the furniture and to achieve success in reducing the production of waste from the use of furniture. Even in the design of furniture, green raw materials can be used as to be degraded in the event of release in nature. Green supply chain management (green supply, green design, green production, green transportation, green packaging) can be planned and implemented in the furniture industry. In this case, it will be possible to obtain environmental certifications for furniture manufacturers.

\section{Key References}

Bessant, J., Whyte, J. and Neely, A. (2005). DTI Think Piece 'Management of creativity and design within the firm', Advanced Institute for Management (AIM) and Imperial College.

Chang, S.H., A.H.I.Lee, and W.L.Pearn. (2005). Analytic network process approach for product mix planning in semiconductor fabricator. Int. J. Prod. Econ. 96(1):15-36.

Gemser, G. and Leenders, M.A.A.M., (2001). 'How integrating industrial design in the product development process impacts on company performance', The Journal of Product Innovation Management, vol.18, pp. 28-38.

Gencer, C., and Gurpinar D., (2007). Analytic network process in supplier selection: A case study in an electronic firm. Applied Mathematical Modeling, Elsevier 31, 2475-2486.

Partovi, Y.F., (2006). An analytic model for locating facilities strategically, OMEGA, Int. J. Manage. Sci. 34(1):41-55.

Ratnasingam J., loras F., (2003). The Sustainability of the Asian Wooden Furniture Industry, European Journal of Wood and Wood Products, Issue 3/2003.

Saaty T., (2001). Decision Making with Dependence and Feedback: The Analytic Network Process: RWS Publications, Pittsburgh, PA. 
Swann, P. and Birke, D. (2005). 'How do Creativity and Design Enhance Business Performance? A framework for interpreting the Evidence', DTI Think Piece, University of Nottingham Business School.

Ulutas, B.H. (2005). determination of appropriate energy policy for Turkey. Energy 30(2005):1146-1161. 